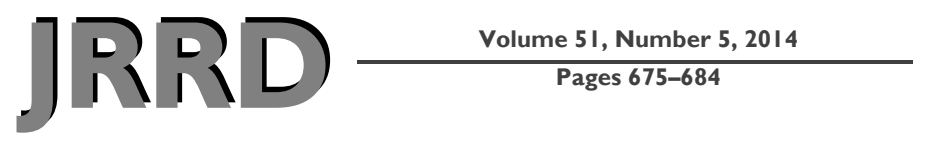

\title{
Homeless and nonhomeless VA service users likely eligible for Medicaid expansion
}

\author{
Jack Tsai, PhD; ${ }^{*}$ Robert A. Rosenheck, $\mathrm{MD}^{1-2}$ \\ ${ }^{1}$ Mental Illness Research, Education, and Clinical Center, Department of Veterans Affairs New England Healthcare \\ System, West Haven, CT; and Department of Psychiatry, Yale School of Medicine, New Haven, CT; ${ }^{2}$ Department of \\ Epidemiology and Public Health, Yale School of Public Health, New Haven, CT
}

\begin{abstract}
Administrative data on the population of Department of Veterans Affairs (VA) service users in 2010 under the age of $65 \mathrm{yr}(n=3,841,225)$ were analyzed to identify the number and characteristics of homeless and nonhomeless VA service users who are likely to be eligible for the Medicaid expansion (LEME) option under the Affordable Care Act. Results showed that, estimating conservatively, about 1.2 million (21\%) current VA users are LEME if all states implement the expansion. Homeless service users were twice as likely to be eligible than nonhomeless users (64\% vs $30 \%$ ). VA service users who are LEME, regardless of housing status, were physically healthier than those not LEME but were more likely to have substance use disorders and posttraumatic stress disorder. These findings suggest that many VA service users are LEME, particularly those who are homeless and/or have mental health needs. Cross-system use of VA and Medicaid-funded services may be advantageous for veterans with extensive medical and psychiatric needs but also risks fragmented care. Information and education for VA clinicians and their patients about possible implications of the Affordable Care Act may be important.
\end{abstract}

Key words: Affordable Care Act, cross-system use, Department of Veterans Affairs, health services, homelessness, Medicaid, posttraumatic stress disorder, psychiatric disorders, substance use disorder, veterans.

\section{INTRODUCTION}

The Patient Protection and Affordable Care Act (ACA) represents a landmark reform of the U.S. healthcare system and is expected to affect millions of American residents [1], including military veterans. The ACA will not directly affect services provided by the Department of Veterans Affairs (VA), VA enrollees will not lose their coverage, and enrollment in VA healthcare will satisfy the ACA's requirement for all legal U.S. citizens to obtain health insurance. But the ACA may introduce new coverage options for VA service users that may affect their healthcare and the delivery of VA services. One of the main components of the ACA is the state option to expand Medicaid to low-income adults. Starting in 2014, the Federal government will pay for Medicaid to be expanded to cover all adults under the age of $65 \mathrm{yr}$ who have a household income $\leq 138$ percent of the Federal poverty level. This will include many lowincome veterans, especially homeless veterans, and may

\footnotetext{
Abbreviations: ACA = Affordable Care Act, FY = fiscal year, HIV/AIDS = human immunodeficiency virus/acquired immune deficiency syndrome, ICD-9 = International Classification of Diseases-9th Revision, LEME = likely to be eligible for the Medicaid expansion, OEF = Operation Enduring Freedom, OIF = Operation Iraqi Freedom, OND = Operation New Dawn, PTSD $=$ posttraumatic stress disorder, VA $=$ Department of Veterans Affairs.

*Address all correspondence to Jack Tsai, PhD; Mental Illness Research, Education, and Clinical Center, VA New England Healthcare System, 950 Campbell Ave (151D), West Haven, CT 06516; 203-932-5711, ext 2090.

Email: Jack.Tsai@yale.edu

http://dx.doi.org/10.1682/JRRD.2013.10.0225 
introduce a new form of coverage for them, which is important because the VA is focused on providing services for homeless veterans [2].

The VA's former Under Secretary for Health, Kenneth Kizer, has discussed several potential pros and cons of the ACA for veterans [3]. Potential pros are new coverage options for uninsured veterans and increased healthcare options for veterans enrolled in VA healthcare. However, potential cons include fragmented care that can occur among veterans with multiple health plans, decreased quality of care because non-VA providers may be less familiar with conditions prevalent among veterans, and provider shortages that may be exacerbated by increased service use among the newly insured. Expanding healthcare insurance may also decrease use of some VA facilities among VA enrollees who obtain non-VA health insurance or may result in redundant spending borne by the U.S. Government among those who use VA and other Federally funded care [3].

Cross-system use, defined as use of more than one healthcare system (e.g., VA and Medicaid-funded providers), is fairly common among VA service users. A largescale survey in 1999 found that 73 percent of veterans enrolled in VA healthcare had alternative healthcare coverage; 53 percent also had Medicare, 19 percent also had private insurance, and 5 percent also had Medicaid [4]. A more recent survey found that 67 percent of VA enrollees under the age of $65 \mathrm{yr}$ also had private insurance, 21 percent also had Medicare, 1 percent also had Medicaid, and 9 percent also had other forms of insurance coverage [5].

The small proportion of veterans currently enrolled in both VA healthcare and Medicaid is likely to substantially increase as eligibility for Medicaid is expanded to all low-income veterans who meet the poverty threshold in states that implement the Medicaid expansion. However, little has been studied to date of potential eligibility for Medicaid coverage among VA service users.

Given the larger proportion of VA enrollees with concurrent Medicare coverage, more studies have been done on this type of dual enrollment, which may be informative in planning for VA service users who will become newly eligible for Medicaid coverage in 2014. Several factors have been identified in the use of Medicarefunded services instead of VA services among veterans dually enrolled in both. Proximity to Medicare-certified providers, unavailability of VA services, no VA serviceconnected disability, and a need for medical services as compared with mental health and substance abuse ser- vices have been found to be associated with greater use of Medicare-funded services among veterans dually enrolled in the VA and Medicare [6-8].

There have been no studies on the ACA, or specifically the Medicaid expansion, on veterans or VA service users. It is important to understand who are likely to be eligible for the Medicaid expansion (LEME) among current VA service users to understand the potential effect of Medicaid expansion in states that implement the expansion and the possible implications of cross-system use [3]. Given the large proportion of homeless veterans, almost universally impoverished, who will likely become eligible for the Medicaid expansion and the VA's focus on preventing homelessness among veterans [2], special attention on the potential effect of the Medicaid expansion among homeless veterans is warranted.

The current study used administrative data on all VA service users in 2010 to (1) estimate the number and proportion of homeless and of nonhomeless VA services users who are LEME, and (2) compare those who are LEME and not LEME on sociodemographic characteristics and medical and psychiatric diagnoses stratified by homeless status. The results will provide an estimate of how many VA service users may be affected by the ACA's Medicaid expansion in 2014 and shed light on their individual characteristics and potential health needs, which may be important in planning for potential crosssystem use.

\section{METHODS}

\section{Study Design}

An observational cross-sectional analysis was conducted using VA administrative data on all veterans under the age of $65 \mathrm{yr}$ who used VA healthcare in fiscal year (FY) 2010 (October 1, 2009-September 30, 2010). National VA administrative data were obtained from several VA workload databases (Patient Treatment File and Outpatient Encounter File) to compare homeless and nonhomeless VA service users who are LEME and not LEME on background characteristics, medical and psychiatric diagnoses, and outpatient service use. All analyses were limited to veterans under the age of $65 \mathrm{yr}$ ( $n=3,841,225$ ) because veterans $65 \mathrm{yr}$ and over have access to Medicare, and Medicare-enrolled elderly adults are not eligible for the Medicaid expansion. 


\section{Sample}

VA service users under the age of 65 yr were divided into homeless $(n=134,234)$ and nonhomeless VA service users $(n=3,706,991)$. Homeless veterans were operationally defined as veterans who had either received any specialized VA homeless services or received an International Classification of Diseases-9th Revision (ICD-9) V60.0 diagnostic code (indicating lack of housing) during FY 2010. This operational definition of homelessness has been used in previous VA studies [9-10].

Homeless and nonhomeless VA service users were then further categorized as LEME or not LEME depending on their income level and VA service-connected disability status. VA service users defined as LEME reported annual income $\leq 138$ percent of the 2010 Federal poverty level (which varies by household size). The household sizes of VA service users were estimated from their marital status and average number of dependent children they are estimated to have under the age of $18 \mathrm{yr}$. While VA administrative data contain information about marital status, they do not include information about dependent children. As a proxy measure of dependents, data from the 2010 National Survey of Veterans were used to obtain information about the average number of dependent children under $18 \mathrm{yr}$ based on their age stratum (under 30, 30-40, 41-50, and $>50 \mathrm{yr}$ ) [11].

VA service users who had a service-connected disability were excluded from being in the LEME group and were categorized as not LEME. The rationale for categorizing veterans with a VA service-connected disability as not LEME is because many receive disability payments that exceed the Medicaid expansion income threshold and because previous studies suggest veterans with a service-connected disability have a strong attachment to the VA and are more likely to be sole users of VA health services, while those not without a VA service-connected disability are more likely to be non-VA service users or cross-system users [8,12].

Based on these definitions, four groups were identified: (1) homeless VA service users who are LEME, (2) homeless VA service users who are not LEME, (3) nonhomeless VA service users who are LEME, and (4) nonhomeless VA service users who are not LEME.

\section{Measures}

Background characteristics included age; sex; race; marital status; income; service in Operation Iraqi Freedom (OIF), Operation Enduring Freedom (OEF), Opera- tion New Dawn (OND); and geographic location. Income data were based on the VA Outpatient Encounter File and VA means test data, which are used to determine eligibility for VA services and are updated regularly. Urban or rural status was documented using zip codes and RuralUrban Commuting Area codes, which are a Census tractbased classification scheme that allows identification of regions as urban locations, small rural communities, large rural communities, or isolated rural communities [13].

Medical and psychiatric diagnoses were based on ICD-9 diagnostic codes entered by VA clinicians in the electronic medical record system. The Charlson Index was applied to the medical conditions of patients to obtain a measure of chronic disease burden [14]. The Charlson Index is a widely used measure of prognostic comorbidity that takes into account the number and seriousness of comorbid medical diseases to predict $10 \mathrm{yr}$ mortality. All qualifying diagnoses (primary or secondary) made in FY 2010 across outpatient and inpatient visits were used to calculate the Charlson Index. The number of mental health and medical visits were also examined, which was based on the total number of psychiatric and primary care, surgical, and/or specialty medical visits in FY 2010.

\section{Data Analysis}

Homeless and nonhomeless VA services users were first analyzed separately on who was LEME, and then differences between homeless and nonhomeless VA service users were examined. First, among homeless VA service users, those who are LEME and not LEME were compared on background characteristics, medical status, and psychiatric status. Given the large sample size and statistical power to detect even tiny differences as significant, relative risk ratios were calculated instead, and statistical significance was not a focus. Relative risk ratios were calculated by dividing the proportions of individuals with the characteristic of interest in each group (e.g., percent male in LEME group vs percent male in not LEME group). These ratios provide an effect size of differences between groups and are easier to interpret and more useful than odds ratios [15]. These analyses were then repeated among nonhomeless VA service users, comparing those who are LEME with those who are not LEME.

Second, differences in relative risk ratios between homeless VA service users LEME and not LEME and between nonhomeless VA services users LEME and not LEME were calculated by subtracting the ratios between the homeless and nonhomeless. These differences provide 
a measure of how eligibility for the Medicaid expansion differs relatively between homeless and nonhomeless VA service users on the characteristics assessed. Traditional tests of significance were not used because data were available on the population of VA service users (not just a sample) and because the large numbers in each group result in statistical power to detect nearly all differences (even very small ones) as significant.

\section{RESULTS}

Of the total sample ( $n=3,841,225), 1,209,293$ (31.48\%) are LEME. Among the homeless $(n=134,234)$, 85,933 (64.02\%) are LEME, while among the nonhomeless ( $n=3,706,991), 1,123,360$ (30.30\%) are LEME. The proportion of VA service users in the four groups were as follows: 2.24 percent were homeless and LEME, 1.26 percent were homeless and not LEME, 29.24 percent were not homeless and LEME, and 67.26 percent were not homeless and not LEME. It should be noted that these are conservative estimates because all VA service users with a VA service-connected disability were categorized as not LEME. When not excluding VA service users with a ser- vice-connected disability, 1,983,798 (51.64\%) of all VA service users are LEME (81.90\% of the homeless and $50.55 \%$ of the nonhomeless). The more conservatively estimated groups were used for the analyses.

Table 1 shows the background characteristics of homeless and nonhomeless VA service users who are LEME compared with those who are not LEME. Among homeless VA service users, those who are LEME were less than half as likely to be married, to be an OIF/OEF/ OND veteran, and to have less than a third of the income of those who are not LEME. By the study definition of LEME, no homeless VA service users who are LEME had a VA service-connected disability while 74.31 percent of those who were not LEME had a VA serviceconnected disability. Among nonhomeless VA service users, the main difference in background characteristics was that those who are LEME had less than a fifth of the income of those who are not LEME. Again, no nonhomeless VA service users had a VA service-connected disability, but 73.99 percent of nonhomeless VA service users who are not LEME had a VA service-connected disability. Comparing differences between homeless VA service users LEME and not LEME with differences between nonhomeless VA service users LEME and not LEME

Table 1.

Background characteristics of homeless and nonhomeless Department of Veterans Affairs (VA) service users likely to be eligible for Medicaid expansion (LEME).

\begin{tabular}{|c|c|c|c|c|c|c|c|}
\hline Characteristic & $\begin{array}{c}\text { Homeless and } \\
\text { LEME } \\
(n=85,933)\end{array}$ & $\begin{array}{l}\text { Homeless and } \\
\text { Not LEME } \\
(n=48,301)\end{array}$ & $\begin{array}{c}\text { Ratio Among } \\
\text { Homeless } \\
\text { (LEME/Not } \\
\text { LEME) }\end{array}$ & $\begin{array}{l}\text { Not Homeless } \\
\text { and LEME } \\
(n=1,123,360)\end{array}$ & $\begin{array}{l}\text { Not Homeless } \\
\text { and Not LEME } \\
(n=2,583,631)\end{array}$ & $\begin{array}{c}\text { Ratio Among } \\
\text { Nonhomeless } \\
\text { (LEME/Not } \\
\text { LEME) }\end{array}$ & $\begin{array}{c}\text { Difference } \\
\text { in Ratios }\end{array}$ \\
\hline Age, yr (mean \pm SD) & $50.73 \pm 8.46$ & $50.43 \pm 11.53$ & 1.01 & $48.39 \pm 12.99$ & $57.47 \pm 14.84$ & 0.84 & 0.16 \\
\hline Male (\%) & 80,708 (93.92) & 43,737 (90.55) & 1.04 & 879,703 (78.31) & 2,387,792 (92.42) & 0.85 & 0.19 \\
\hline White (\%) & 11,979 (13.94) & 8,854 (18.33) & 0.76 & 133,515 (11.88) & 529,644 (20.50) & 0.58 & 0.18 \\
\hline Married (\%) & 8,361 (9.73) & $10,066(20.84)$ & 0.47 & $342,400(30.48)$ & $1,559,220(60.35)$ & 0.51 & -0.04 \\
\hline $\begin{array}{l}\text { OIF/OEF/OND } \\
\text { Status (\%) }\end{array}$ & 3,515 (4.09) & 4,405 (9.12) & 0.45 & $146,214(13.01)$ & 246,995 (9.56) & 1.36 & -0.91 \\
\hline $\begin{array}{l}\text { Income, USD } \\
\quad(\text { mean } \pm \text { SD) }\end{array}$ & $4,711.66 \pm 5,642.50$ & $19,924.62 \pm 23,682.77$ & 0.24 & $3,780.58 \pm 5,983.46$ & $35,724.87 \pm 61,471.77$ & 0.11 & 0.13 \\
\hline \multicolumn{8}{|l|}{$\begin{array}{l}\text { VA Service Connected } \\
\text { Disability (\%) }\end{array}$} \\
\hline$<50 \%$ & $0(0.00)^{*}$ & 21,069 (43.62) & 0.00 & $0(0.00)$ & $976,871(37.81)$ & 0.00 & 0.00 \\
\hline$\geq 50 \%$ & $0(0.00)$ & 14,824 (30.69) & 0.00 & $0(0.00)$ & 934,758 (36.18) & 0.00 & 0.00 \\
\hline \multicolumn{8}{|l|}{ Geographic Region (\%) } \\
\hline Urban & 76,171 (88.64) & 73,602 (85.65) & 1.03 & 840,647 (74.80) & $1,820,170(70.45)$ & 1.06 & -0.03 \\
\hline Small Rural & 2,724 (3.17) & $2,116(4.38)$ & 0.72 & 89,122 (7.93) & 258,245 (9.62) & 0.82 & -0.10 \\
\hline Large Rural & $5,362(6.24)$ & 3,396 (7.03) & 0.89 & 126,884 (11.29) & 314,686 (12.18) & 0.93 & -0.04 \\
\hline Isolated Rural & $1,676(1.95)$ & $1,420(2.94)$ & 0.66 & 67,319 (5.99) & $200,490(7.76)$ & 0.77 & -0.11 \\
\hline
\end{tabular}


(i.e., difference in ratios), we found few notable differences, although the largest difference showed that nonhomeless VA service users who are LEME were more likely to be OIF/OEF/OND veterans.

As shown in Table 2, homeless VA service users who are LEME had a lower Charlson Index score and were less likely than those who are not LEME to have various medical conditions, except liver disease and human immunodeficiency virus/acquired immune deficiency syndrome (HIV/AIDS). A similar pattern was observed among nonhomeless VA service users, with those who are LEME being less likely to have all medical conditions, except liver disease and HIV/AIDS. There was little difference in the ratios of these medical conditions between homeless and nonhomeless VA service users based on eligibility for the Medicaid expansion, except nonhomeless VA service users who are LEME had a relatively greater likelihood of having HIV/AIDS than homeless VA service users.

In examining psychiatric diagnoses (Table 3), homeless VA service users who are LEME were slightly more likely to have substance use disorders and major depressive disorder and nearly two times more likely to have posttraumatic stress disorder (PTSD) than those not LEME. Similarly, among nonhomeless VA service users, those who are LEME were more likely to have substance use disorders and nearly three times more likely to have PTSD than those not LEME but were less likely to have major depressive disorder. The differences in ratios

Table 2.

Medical status of homeless and nonhomeless Department of Veterans Affairs service users likely to be eligible for Medicaid expansion (LEME).

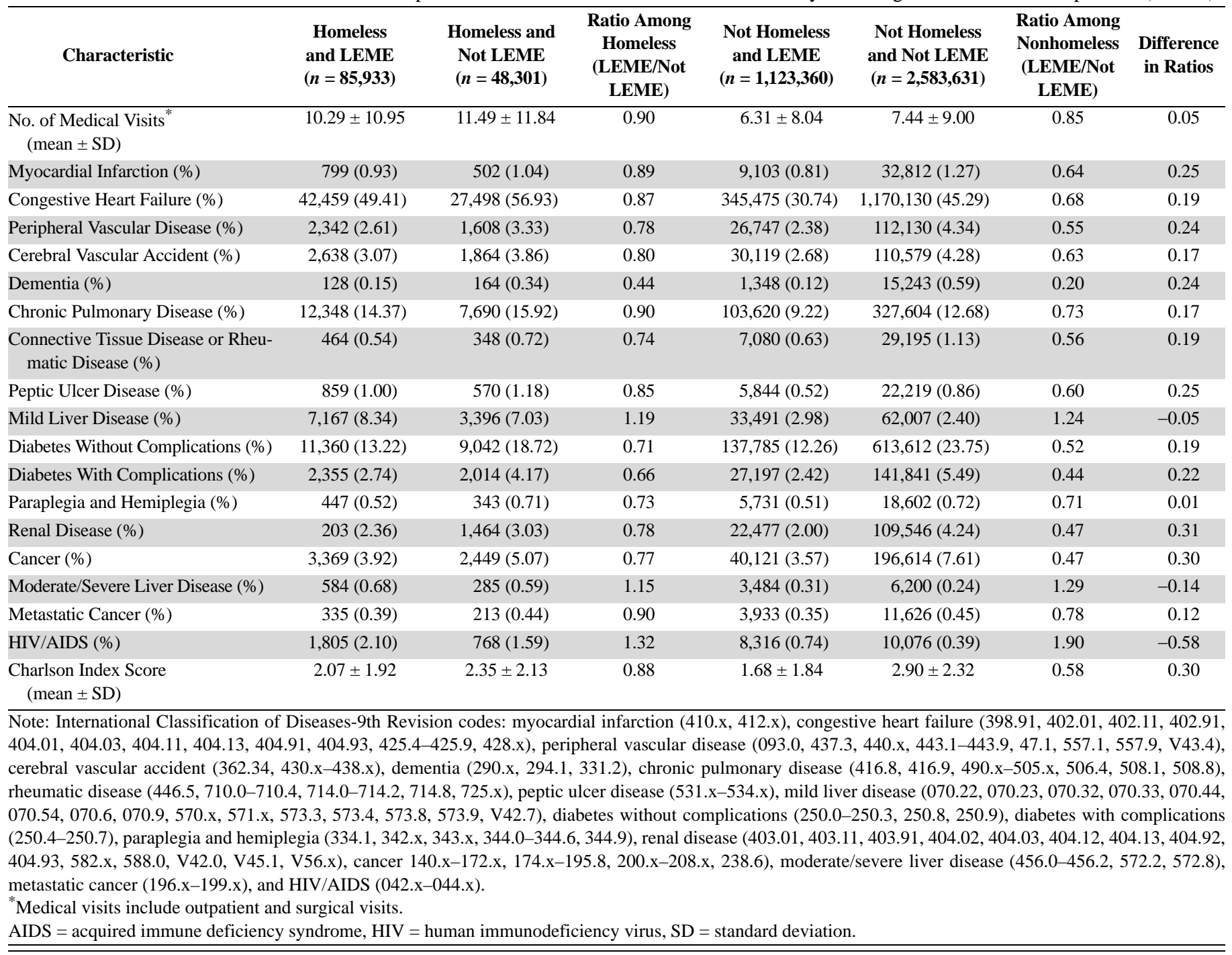


Table 3.

Psychiatric status among homeless and nonhomeless Department of Veterans Affairs service users likely to be eligible for Medicaid expansion (LEME).

\begin{tabular}{|c|c|c|c|c|c|c|c|}
\hline Characteristic & $\begin{array}{c}\text { Homeless and } \\
\text { LEME } \\
(n=85,933)\end{array}$ & $\begin{array}{l}\text { Homeless and } \\
\text { Not LEME } \\
(n=48,301)\end{array}$ & $\begin{array}{l}\text { Ratio Among } \\
\text { Homeless } \\
\text { (LEME/Not } \\
\text { LEME) }\end{array}$ & $\begin{array}{l}\text { Not Homeless } \\
\text { and LEME } \\
(n=1,123,360)\end{array}$ & $\begin{array}{l}\text { Not Homeless } \\
\text { and Not LEME } \\
(n=2,583,631)\end{array}$ & $\begin{array}{c}\text { Ratio Among } \\
\text { Nonhomeless } \\
\text { (LEME/Not } \\
\text { LEME) }\end{array}$ & $\begin{array}{l}\text { Difference } \\
\text { in Ratios }\end{array}$ \\
\hline $\begin{array}{l}\text { No. of Mental Health Visits* } \\
\quad(\text { mean } \pm \text { SD) }\end{array}$ & $31.97 \pm 52.39$ & $29.45 \pm 50.01$ & 1.09 & $2.27 \pm 13.02$ & $2.73 \pm 12.07$ & 0.83 & 0.25 \\
\hline Alcohol Use Disorder (\%) & $37,304(43.41)$ & $17,320(35.86)$ & 1.22 & 89,796 (7.99) & $148,042(5.73)$ & 1.39 & -0.17 \\
\hline Drug Use Disorder (\%) & $40,405(47.02)$ & $18,528(38.36)$ & 1.23 & 65,858 (5.86) & $82,676(3.20)$ & 1.83 & -0.61 \\
\hline Schizophrenia (\%) & $6,754(7.86)$ & $4,806(9.95)$ & 0.79 & $20,229(1.80)$ & $53,223(2.06)$ & 0.87 & -0.08 \\
\hline Other Psychosis (\%) & $4,606(5.36)$ & $2,550(5.28)$ & 1.02 & $9,777(0.87)$ & 23,769 (0.92) & 0.95 & 0.07 \\
\hline Bipolar Disorder (\%) & $9,221(10.73)$ & $5,434(11.25)$ & 0.95 & $26,298(2.34)$ & $59,423(2.30)$ & 1.02 & -0.06 \\
\hline Major Depressive Disorder (\%) & $17,461(20.32)$ & 7,964 (16.49) & 1.23 & $55,518(4.94)$ & $175,687(6.80)$ & 0.73 & 0.50 \\
\hline Other Affective Disorder (\%) & 36,083 (41.99) & 19,156 (39.66) & 1.06 & 192,854 (17.16) & $367,392(14.22)$ & 1.21 & -0.12 \\
\hline Posttraumatic Stress Disorder (\%) & 27,645 (32.17) & 8,206 (16.99) & 1.89 & $187,460(16.68)$ & $169,228(6.55)$ & 2.55 & -0.66 \\
\hline Other Anxiety Disorder (\%) & 17,693 (20.59) & 8,757 (18.13) & 1.14 & $100,698(8.96)$ & 202,298 (7.83) & 1.14 & 0.00 \\
\hline Adjustment Disorder (\%) & $13,543(15.76)$ & $7,690(15.92)$ & 0.99 & $38,436(3.42)$ & $81,384(3.15)$ & 1.09 & -0.10 \\
\hline Personality Disorder (\%) & $6,204(7.22)$ & $3,521(7.29)$ & 0.99 & $10,227(0.91)$ & 26,094 (1.01) & 0.90 & 0.09 \\
\hline Any Psychiatric Disorder (\%) & 71,229 (82.89) & 38,993 (80.73) & 1.03 & $461,457(41.06)$ & 848,723 (32.85) & 1.25 & -0.22 \\
\hline Dual Diagnosis (\%) & $40,973(47.68)$ & $27,430(56.79)$ & 0.84 & $99,686(8.87)$ & $161,735(6.26)$ & 1.42 & -0.58 \\
\hline \multicolumn{8}{|c|}{$\begin{array}{l}\text { Note: International Classification of Diseases-9th Revision codes: alcohol use disorders (303.xx, 305.00), drug use disorders (29.201-292.99, 304.xx, 305.20- } \\
\text { 305.99), schizophrenia (295.xx), other psychosis (297.xx-299.xx), bipolar disorder (296.0x, 296.1x, 296.40-296.89), major depressive disorder (296.2-296.39), } \\
\text { other affective disorder (300.4x, 296.9x, 311.xx, 301.10-301.19), posttraumatic stress disorder (309.81), other anxiety disorders (300.xx, excluding 300.4), adjust- } \\
\text { ment disorder (309.xx, excluding 309.81), and personality disorder (301.0x, 301.2x-301.99). } \\
{ }^{*} \text { Mental health visits include psychiatric and substance abuse visits. }\end{array}$} \\
\hline
\end{tabular}

between homeless and nonhomeless VA service use on psychiatric conditions based on eligibility for the Medicaid expansion showed that homeless VA service users had a greater likelihood of having major depressive disorder (compared with their ineligible counterparts) than homeless VA service users who are LEME (compared with their ineligible counterparts) but had a lower likelihood of having drug use disorders, PTSD, and dual diagnoses.

\section{DISCUSSION}

Among all VA service users under the age of $65 \mathrm{yr}$, homeless service users are two times more LEME than nonhomeless service users (64\% vs $30 \%$ ), which is important to consider because the VA has a national initiative to serve homeless veterans [2]. While it might be expected that the majority of homeless VA service users would be LEME given their low incomes, nearly a third of nonhomeless VA service users under $65 \mathrm{yr}$ are also LEME. Notably, nonhomeless VA services users who are LEME were younger and more likely to be OIF/OEF/
OND veterans than those who are not LEME. Thus, the potential effect of the Medicaid expansion may be particularly pertinent for returning OIF/OEF/OND veterans [3].

These numbers suggest there may be an increase in cross-system use as veterans enrolled in VA care become newly eligible for Medicaid. While this may increase access to care by providing VA service users with more coverage options, it may also lead to more fragmented care as patients receive different, and sometimes the same, services across different systems [3]. Therefore, it may be important for VA clinicians to be adequately educated about the ACA so they can communicate with their patients on its implications as well as provide and obtain information from outside providers to coordinate care in the case of cross-system use. It is important for VA patients to understand any new coverage options they may have under the ACA. The VA has created a Web site educating veterans specifically about how the ACA will not affect their VA services and that enrollment in VA care satisfies the individual mandate for health insurance [16].

With the potential for increased dual enrollment among veterans, there may be more opportunities for the 
VA to develop community-partnered services and formalized communication channels to coordinate care with outside providers. These opportunities may be important to control variability in care and ensure the best possible patient outcomes [17-19]. With the VA's great advances in integrating technology into healthcare delivery, this technology may be utilized to improve care coordination [20-22]. For example, the VA's online personal record system, My HealtheVet, could potentially incorporate provider-to-provider secure messaging. Exploring ways for VA patients and clinicians to communicate with nonVA providers through technology or including them in the delivery of VA technology-assisted programs should be considered.

VA service users who are LEME, regardless of housing status, were generally physically healthier than those not LEME, except they were more likely to have liver disease and HIV/AIDS, which may be notable because these are conditions that can be costly to treat. Not surprisingly, homeless VA service users, regardless of Medicaid-eligibility status, were more likely to have various psychiatric conditions than nonhomeless VA service users, consistent with various studies showing the high prevalence of psychiatric disorders among homeless individuals [23-24]. This finding demonstrates the need for homeless veterans to have comprehensive services, whether it is provided at the VA, outside the VA, or both. It is important to note, though, that some of the comprehensive social services and substance abuse treatment offered at the VA will not be covered by Medicaid. This may either dampen the effect of dual eligibility and enrollment or may result in use of non-VA providers only for more specialized services.

Among both homeless and nonhomeless VA service users, those who are LEME were more likely to have substance use disorders and PTSD than those not LEME. The higher prevalence of PTSD among those who are LEME may be of concern if these VA service users decide to use Medicaid-funded services for their PTSD, because non-VA providers may be less prepared and trained to treat this condition and its sequelae [3]. The finding of higher prevalence of substance use disorders among those who are LEME may be important to consider because the Medicaid expansion is expected to change the delivery of public substance abuse treatment services. Reform provisions from the ACA are likely to expand the variety of treatment providers while shifting services away from residential and stand-alone programs toward outpatient and integrated programs [25]. Thus, some VA service users who seek non-VA substance abuse treatment may experience these changes.

This study has several limitations worth noting. VA administrative data were used, which rely on the clinical documentation and diagnoses of VA clinicians. The number of dependents veterans had were based on national averages, so were imprecise. Only VA service users were examined, and so the findings do not include the estimated 1.8 million uninsured veterans who could benefit greatly from the Medicaid expansion [26]. Furthermore, the data only address the likely eligibility of veterans for the Medicaid expansion and it could not be determined from VA administrative data who is currently already eligible for Medicaid but not enrolled. Also, it is yet unclear how many states will actually implement the expansion because some states remain undecided. Currently, there is no time limit on participation and presumably all states could eventually participate. The difference in eligibility and enrollment also needs to be emphasized, because many veterans may become eligible but may not actually enroll in Medicaid. In addition, a probabilistic assumption was made that veterans with service-connected disabilities would not enroll in Medicaid, which likely yielded underestimates of how many veterans are LEME. Finally, it can only be speculated what differences between veterans who are LEME and not LEME will mean and how it will affect different states until the expansion is actually implemented.

\section{CONCLUSIONS}

At least one-fifth of all VA service users, including the majority of homeless service users, may be eligible for the Medicaid expansion in 2014 in states that implement the expansion. The VA should anticipate potential increases in cross-system use among its patients, particularly for those in need of mental health services. Specifically, efforts should focus on capitalizing on the increased coverage options available to veterans under the ACA and reducing the fragmented care that may result from cross-system use. Information about the ACA and education for VA clinicians and their patients about its implications may be important to ensure that veterans benefit from the nation's current healthcare reform. 


\section{ACKNOWLEDGMENTS}

\section{Author Contributions:}

Study concept and design: J. Tsai, R. A. Rosenheck.

Acquisition of data: R. A. Rosenheck.

Analysis of data: J. Tsai.

Drafting of manuscript: J. Tsai, R. A. Rosenheck.

Financial Disclosures: The authors have declared that no competing interests exist.

Funding/Support: This material was based on work supported by the VA, Veterans Health Administration, Office of Research and Development.

Institutional Review: Use of these data and study procedures were approved as exempt status from the institutional review board at the VA Connecticut Healthcare System.

Disclaimer: The views presented here are those of the authors alone and do not represent the position of any Federal agency or of the U.S. Government.

\section{REFERENCES}

1. Koh HK, Sebelius KG. Promoting prevention through the Affordable Care Act. N Engl J Med. 2010;363(14):1296-99. [PMID:20879876] http://dx.doi.org/10.1056/NEJMp1008560

2. Secretary Shinseki details plans to end homelessness for veterans [Internet]. Washington (DC): Office of Public and Intergovernmental Affairs, Department of Veterans Affairs; 2009 Nov 3. Available from: http://www1.va.gov/opa/ pressrel/pressrelease.cfm?id=1807

3. Kizer KW. Veterans and the Affordable Care Act. JAMA. 2012;307(8):789-90. [PMID:22357828] http://dx.doi.org/10.1001/jama.2012.196

4. Shen Y, Hendricks A, Zhang S, Kazis LE. VHA enrollees' health care coverage and use of care. Med Care Res Rev. 2003;60(2):253-67. [PMID:12800686] http://dx.doi.org/10.1177/1077558703060002007

5. Nelson KM, Starkebaum GA, Reiber GE. Veterans using and uninsured veterans not using Veterans Affairs (VA) health care. Public Health Rep. 2007;122(1):93-100. [PMID:17236614]

6. Petersen LA, Byrne MM, Daw CN, Hasche J, Reis B, Pietz $\mathrm{K}$. Relationship between clinical conditions and use of Veterans Affairs health care among Medicare-enrolled veterans. Health Serv Res. 2010;45(3):762-91. [PMID:20403056] http://dx.doi.org/10.1111/j.1475-6773.2010.01107.x

7. Carey K, Montez-Rath ME, Rosen AK, Christiansen CL, Loveland S, Ettner SL. Use of VA and Medicare services by dually eligible veterans with psychiatric problems. Health Serv Res. 2008;43(4):1164-83. [PMID:18355256] http://dx.doi.org/10.1111/j.1475-6773.2008.00840.x
8. Shen Y, Hendricks A, Li D, Gardner J, Kazis L. VA-Medicare dual beneficiaries' enrollment in Medicare HMOs: Access to VA, availability of HMOs, and favorable selection. Med Care Res Rev. 2005;62(4):479-95. [PMID:16049135] http://dx.doi.org/10.1177/1077558705277396

9. Tsai J, Edens EL, Rosenheck RA. Nicotine dependence and its risk factors among users of veterans health services, 2008-2009. Prev Chronic Dis. 2011;8(6):A127. [PMID:22005620]

10. Tsai J, Rosenheck RA. Risk factors for ED use among homeless veterans. Am J Emerg Med. 2013;31(5):855-58. [PMID:23566404] http://dx.doi.org/10.1016/j.ajem.2013.02.046

11. National Survey of Veterans, Active Duty Service Members, Demobilized National Guard and Reserve Members, Family Members, and Surviving Spouses [Internet]. Appendix B: National survey of veterans detailed description of weighting procedures. Rockville (MD): Westat; 2010. Available from: http://www.va.gov/vetdata/docs/SurveysAndStudies/ AppendixBWeightingProcedures.pdf

12. Hoff RA, Rosenheck RA. Cross-system service use among psychiatric patients: Data from the Department of Veterans Affairs. J Behav Health Serv Res. 2000;27(1):98-106. [PMID:10695244] http://dx.doi.org/10.1007/BF02287807

13. WWAMI Rural Health Research Center [Internet]. Ruralurban commuting area codes (RUCAs). Seattle (WA): WWAMI Rural Health Research Center, Department of Family Medicine, University of Washington; 2005 [cited 2013 Apr 10]. Available from: http://depts.washington.edu/ uwruca/index.php

14. Charlson ME, Pompei P, Ales KL, MacKenzie CR. A new method of classifying prognostic comorbidity in longitudinal studies: Development and validation. J Chronic Dis. 1987;40(5):373-83. [PMID:3558716] http://dx.doi.org/10.1016/0021-9681(87)90171-8

15. Osborne JW. Bringing balance and technical accuracy to reporting odds ratios and the results of logistic regression analyses. Pract Assess Res Eval. 2006;11(7):1-6.

16. U.S. Department of Veterans Affairs [Internet]. VA, Affordable Care Act, and you. Washington (DC): U.S. Department of Veterans Affairs; 2013 [cited 2013 Oct 11]. Available from: http://www.va.gov/health/aca/

17. Wright SM, Daley J, Fisher ES, Thibault GE. Where do elderly veterans obtain care for acute myocardial infarction: Department of Veterans Affairs or Medicare? Health Serv Res. 1997;31(6):739-54. [PMID:9018214]

18. Borowsky SJ, Cowper DC. Dual use of VA and non-VA primary care. J Gen Intern Med. 1999;14(5):274-80. [PMID:10337036] http://dx.doi.org/10.1046/j.1525-1497.1999.00335.x 
19. Bean-Mayberry B, Chang CC, McNeil M, Hayes P, Scholle $\mathrm{SH}$. Comprehensive care for women veterans: Indicators of dual use of VA and non-VA providers. J Am Med Womens Assoc. 2004;59(3):192-97. [PMID:15354372]

20. Tsai J, Rosenheck RA. Use of the internet and an online personal health record system by US veterans: Comparison of Veterans Affairs mental health service users and other veterans nationally. J Am Med Inform Assoc. 2012;19(6): 1089-94. [PMID:22847305] http://dx.doi.org/10.1136/amiajnl-2012-000971

21. Woodend AK, Sherrard H, Fraser M, Stuewe L, Cheung T, Struthers C. Telehome monitoring in patients with cardiac disease who are at high risk of readmission. Heart Lung. 2008;37(1):36-45. [PMID:18206525]

http://dx.doi.org/10.1016/j.hrtlng.2007.04.004

22. Godleski L, Darkins A, Peters J. Outcomes of 98,609 U.S. Department of Veterans Affairs patients enrolled in telemental health services, 2006-2010. Psychiatr Serv. 2012; 63(4):383-85. [PMID:22476305] http://dx.doi.org/10.1176/appi.ps.201100206

23. Gelberg L, Linn LS, Leake BD. Mental health, alcohol and drug use, and criminal history among homeless adults. Am J Psychiatry. 1988;145(2):191-96. [PMID:3341464]

24. Tsai J, Mares AS, Rosenheck RA. Do homeless veterans have the same needs and outcomes as non-veterans? Mil Med. 2012;177(1):27-31. [PMID:22338975] http://dx.doi.org/10.7205/MILMED-D-11-00128
25. Buck JA. The looming expansion and transformation of public substance abuse treatment under the Affordable Care Act. Health Aff (Millwood). 2011;30(8):1402-10.

[PMID:21821557] http://dx.doi.org/10.1377/hlthaff.2011.0480

26. Himmelstein DU, Lasser KE, McCormick D, Bor DH, Boyd JW, Woolhandler S. Lack of health coverage among US veterans from 1987 to 2004. Am J Public Health. 2007; 97(12):2199-2203. [PMID:17971547] http://dx.doi.org/10.2105/AJPH.2006.106302

Submitted for publication October 22, 2013. Accepted in revised form January 8, 2014.

This article and any supplementary material should be cited as follows:

Tsai J, Rosenheck RA. Homeless and nonhomeless VA service users likely eligible for Medicaid expansion. J Rehabil Res Dev. 2014;51(5):675-84.

http://dx.doi.org/10.1682/JRRD.2013.10.0225

ResearcherID/ORCID: Jack Tsai, PhD: 0000-0002-0329$648 X$

\begin{tabular}{|c|c|}
\hline $\begin{array}{l}\text { Au suemssions screeneo gr. } \\
\text { iThenticate }\end{array}$ & ef \\
\hline mant Tor & $\begin{array}{l}\text { CROSSREF.ORG } \\
\text { THE CITATIOH LIIKIHG EACKEOHE }\end{array}$ \\
\hline
\end{tabular}


